\title{
Analisis Pengaruh Temperatur Mold terhadap Perpindahan Kalor pada Polimer dalam Proses Injection Molding Menggunakan Software Autodesk Moldflow Adviser
}

\author{
Suhaeri $^{1}$, Sugiyarto ${ }^{1}$, R.P. Wardhani ${ }^{2}$, dan Djuhana ${ }^{1}$ \\ ${ }^{1}$ Program Studi Teknik Mesin, Universitas Pamulang, Jl. Surya Kencana No.1, Pamulang 15417, \\ Tangerang Selatan, Indonesia. \\ ${ }^{2}$ Program Studi Tekniik Mesin, Universitas Tridharma, Balikpapan utara, Balikpapan 76126, Indonesia
}

E-mail: Sugiyarto784@gmail.com

Masuk : 20 November 2020

Direvisi : 1Desember 2020

Disetujui :5 Januari 2021

\begin{abstract}
Abstrak: Penelitian ini dilakukan untuk mengetahui pengaruh temperatur mold terhadap perpindahan kalor dalam polimer dan pengaruhnya terhadap cacat produk yang terjadi pada kover dudukan pelat sepeda motor. Produk ini terbuat dari plastik dan diproduksi dengan metode injection molding. Penelitian ini dilakukan menggunakan software Autodesk Moldflow Adviser. Dari hasil penelitian tersebut diketahui bahwa terjadi perpindahan kalor sebesar 80.213,68 Joule pada temperature mold $30^{\circ} \mathrm{C}, 60.689,01$ Joule pada temperature mold $40^{\circ} \mathrm{C}$ dan $54.425,55$ Joule pada temperature mold $50^{\circ} \mathrm{C}$. Potensi cacat produk sink mark sebesar $0,1084 \mathrm{~mm}$ pada temperature mold $30^{\circ} \mathrm{C}, 0,1124 \mathrm{~mm}$ pada temperature mold $40^{\circ} \mathrm{C}$, dan 0,1169 $\mathrm{mm}$ pada temperature mold $50^{\circ} \mathrm{C}$. Potensi cacat warpage sebesar $1,418 \mathrm{~mm}$ pada suhu $30^{\circ} \mathrm{C}, 1,521 \mathrm{~mm}$ pada suhu $40^{\circ} \mathrm{C}$, dan $1,6382 \mathrm{~mm}$ pada suhu $50^{\circ} \mathrm{C}$. Pada temperature mold $50^{\circ} \mathrm{C}$ didapatkan parameter setting yang lebih efektif dan efisien.
\end{abstract}

Kata kunci: Injection molding, polimer, perpindahan kalor, temperatur mold, sinkmark, warpage

\begin{abstract}
The research was conducted to obtain temperature mold influence on the heat transfer polymer and influence of deformities product happened on cover motorcycle plate holder. This product made od plastic and produced with the injection molding. The research was conducted uses autodesk moldflow adviser software. Of this research note that happened displacement heat engine of 80.213,68 Joule in $30^{\circ} \mathrm{C}$ mold temperature, $60.689,01$ Joule in $40^{\circ} \mathrm{C}$ mold temperature, $54.435,55$ Joule in $50^{\circ} \mathrm{C}$ mold temperature. Defective sinkmark potential on product of $0,1084 \mathrm{~mm}$ in $30^{\circ} \mathrm{C}$ mold temperature, $0,1124 \mathrm{~mm}$ in $40^{\circ} \mathrm{C}$ mold temperature, and $0,1169 \mathrm{~mm}$ in $50^{\circ} \mathrm{C}$ mold temperature. Defct warpage potentially of $1,418 \mathrm{~mm}$ in $30^{\circ} \mathrm{C}$ mold temperature, $1,521 \mathrm{~mm}$ in $40^{\circ} \mathrm{C}$ mold temperature, and $1,6382 \mathrm{~mm}$ in $50^{\circ} \mathrm{C}$ mold temperature. In $50^{\circ} \mathrm{C}$ mold temperatiure obtained parameter setting more effective and efficient.
\end{abstract}

Keywords: Injection molding, polymer, heat transfer, mold temperature, sinkmark, warpage

\section{PENDAHULUAN}

Perkembangan dunia otomotif tiap hari kian meningkat. Berbagai jenis kendaran bermotor silih berganti dikeluarkan oleh perusahaan-perusahaan produsen sepeda motor baik dalam negeri maupun luar negeri. Banyaknya varian sepeda motor yang diproduksi berhasil menjangkau hampir semua elemen masyarakat.

Dengan minat dan daya beli masyarakat terhadap sepeda motor yang cukup tinggi, produsen sepeda motor melakukan berbagai inovasi terhadap produk-produk mereka. Dari desain yang dibuat semenarik mungkin, harga yang bersaing, dan penambahan aksesori untuk membuat sepeda motor menjadi lebih menarik.

Salah satu produk aksesoris sepeda motor yang akhir-akhir ini mulai lazim digunakan adalah kover dudukan pelat sepda motor. Produk ini berfungsi sebagai dudukan atau tempat pelat sepeda motor, untuk 
mempermudah pemasangan pelat, dan juga melindungi pelat sepeda motor. Produk ini umumnya terbuat dari material plastik, karena ringan dan murah [1-3].

Pembuatan produk ini dilakukan melalui proses injection molding. Dengan metode ini produk yang dihasilkan akan lebih presisi, selain itu dari segi produksi akan lebih efektif dan efisien. Untuk mendapaktan produk yang berkualistas bagus selain dari kualitas cetakan, juga diperlukan setting parameter yang tepat pada saat proses injeksi [1], [4].

Sebelum atau pada saat proses pembuatan desain mold, akan dilakukan proses CAE ( computer aided engineering), yaitu analisis terhadap produk, guna membantu proses pembuatan desain mold sehingga mendapatkan produk yang berkualitas. Proses CAE pada umumnya dilakukan dengan bantuan software simulasi, yang nantinya akan menghasilkan analisis terhadap potensi masalah yg mungkin terjadi pada mold atau produk, sehingga dapat diantisipasi dari awal pada saat proses desain mold. Selain itu juga akan didapatkan parameter setting yang hampir mendekati aktual, sehingga proses trial and eror akan lebif efektif [5-7].

Pada kesempatan kali ini penulis akan melakukan penelitian pra-produksi pada proses pembuatan mold kover dudukan pelat sepeda motor. Penelitian ini dilakukan sebelum atau bersamaan dengan proses desain mold. Analisis yang dilakukan adalah pengaruh temperatur mold terhadap proses perpindahan kalor yang terjadi pada polimer dalam proses injeksi. Selain itu juga akan dilihat pengaruhnya terhadap potensi cacat produk yang akan timbul, yaitu warepage dan sink mark. Penelitian ini dilakukan menggunakan software simulasi, yaitu Autodesk Moldflor Adviser, dengan variasi temperatur $\operatorname{mold} 30^{\circ} \mathrm{C}, 40^{\circ} \mathrm{C}$, dan $50^{\circ} \mathrm{C}$ [7-9].

\section{METODOLOGI}

Penelitian dilakukan menggunkan software simulasi Autodesk Moldflow Adviser untuk dapat mengetahui pengaruh variasi temperatur mold terhadap proses perpindahan kalor dalam polimer proses Injection Molding, beserta pengaruhnya terhadap cacat produk khususnya warepage dan sinkmark. Instrumen penelitian ini menggunakan mold dudukan kover pelat motor dengan material produk polyprophylene $(P P)$. Parameter yang divariasi adalah temperatur mold, dengan variasi $30^{\circ} \mathrm{C}, 40^{\circ} \mathrm{C}$, dan $50^{\circ} \mathrm{C}$.

\section{HASIL DAN PEMBAHASAN}

\section{Hasil simulasi injeksi}

Hasil simulasi injeksi dengan melt temperature material yang ditahan pada suhu $200^{\circ} \mathrm{C}$ dan dengan variabel temperatur mold yang berbeda yaitu $30^{\circ} \mathrm{C}, 40^{\circ} \mathrm{C}$, dan $50^{\circ} \mathrm{C}$ :

\begin{tabular}{|l|c|c|c|}
\hline $\begin{array}{l}\text { Mold temperatur } \\
\left({ }^{\circ} \mathrm{C}\right)\end{array}$ & 30 & 40 & 50 \\
\hline $\begin{array}{l}\text { Melt temperatur } \\
\left({ }^{\circ} \mathrm{C}\right)\end{array}$ & 200 & 200 & 200 \\
\hline $\begin{array}{l}\text { Part temperatur } \\
\left({ }^{\circ} \mathrm{C}\right)\end{array}$ & 36,1 & 38,2 & 39,08 \\
\hline Cycle time $(\mathrm{s})$ & 114,39 & 86,88 & 78,37 \\
\hline
\end{tabular}

Gambar 1. Hasil simulasi injeksi

Dari hasil simulasi dapat dilihat jika part temperature berbanding lurus dengan mold temperature, sedanglan cycle time berbanding terbalik dengan mold temperature. 


\section{Analisis perpindahan kalor}

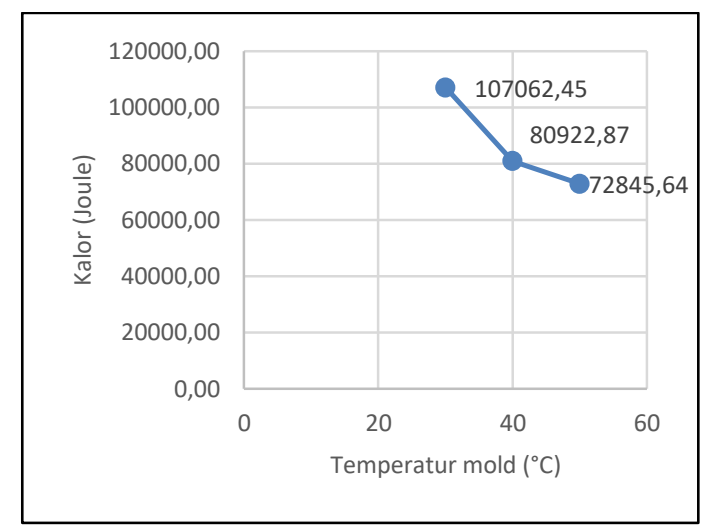

Gambar 2. Perpindahan kalor pada polimer

Berdasarkan hasil simulasi kemudian dihitung perpindahan kalor yang terjadi pada polimer, pada temperatur mold $30^{\circ} \mathrm{C}$ perpindahan kalor yang terjadi $107.062,45$ Joule, pada temperatur mold $40^{\circ} \mathrm{C}$ sebesar $80.922,87$ Joule, dan pada temperatur mold $50^{\circ} \mathrm{C}$ sebesar $72.845,64$ Joule. Perpindahan kalor yang terjadi berbanding terbalik dengan mold temperatur, semakin tinggi temperatur mold maka kalor yg berpindah semakin kecil. Hal ini dipengaruhi oleh cycle time yg semakin kecil, sehingga perindahan kalor yg terjadi juga semakin kecil [10].

\section{Cacat produk sinkmark dan warpage}

Potensi cacat sinkmark berdasarkan hasil simulasi:

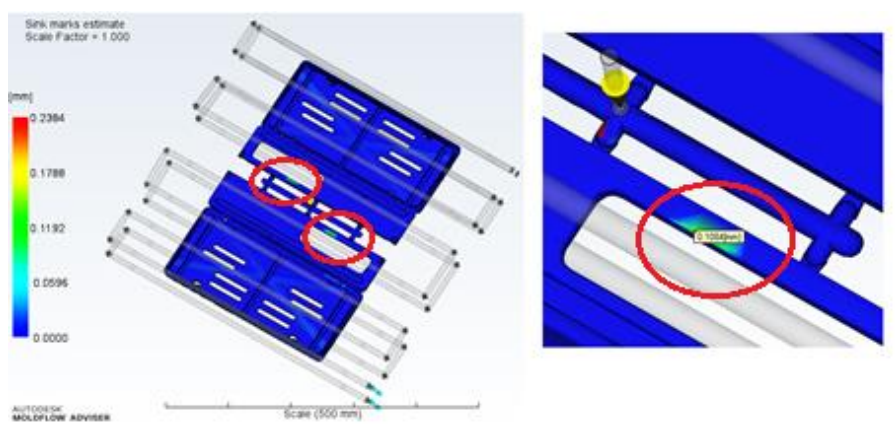

Gambar 3. Posisi potensi cacat sinkmark pada produk

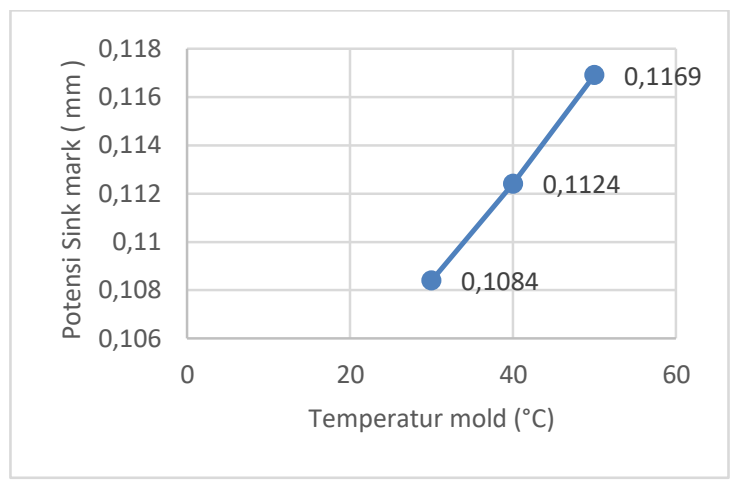

Gambar 4. Besaran potensi cacat sinkmark

Perbedaan potensi sinkmark pada setiap temperatur mold sangat kecil, jadi tidak akan mempengaruhi kualitas produk.

Potensi cacat warpage berdasarkan hasil simulasi injeksi: 


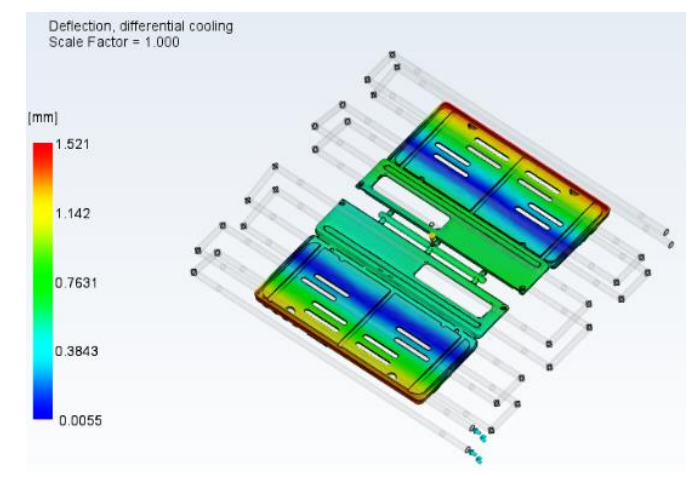

Gambar 5. Potensi cacat warpage

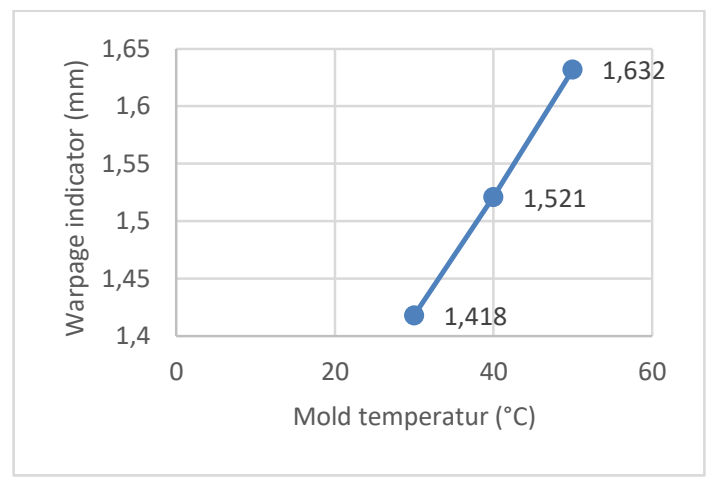

Gambar 6. Besaran potensi cacat warpage

Kenaikan nilai potensi warpage konstan terhadap kenaikan temmperature mold. Nilai potensi warpage untuk tiga kali simulasi yang dilakukan dengan variabel temperatur mold yang berbeda berada di kisaran 1,4 $\mathrm{mm}$ sampai $1,7 \mathrm{~mm}$. Dari hasil yang diperoleh, besaran nilai warpage masih masuk dalam toleransi kualitas produk yang diinginkan. Hal ini dikarenakan produk ini tidak berpasangan dengan produk plastik lain, jadi potensi warpage yang terjadi dengan nilai tersebut masih aman [11].

\section{KESIMPULAN}

Berdasarkan hasil penelitian dan analisis data yang mengacu pada perumusan masalah, maka dapat disimpulkan sebagai berikut :

1. Perpindahan kalor yang terjadi pada polimer pada saat proses injeksi berbanding terbalik dengan temperatur mold, yang artinya jika temperatur mold dinaikan maka perpindahan kalor yang terjadi akan semakin kecil. Hal ini dipengaruhi oleh temperatur produk setelah proses injeksi yang berbanding lurus dengan temperatur mold, yaitu $36,10^{\circ} \mathrm{C}$ pada tempertaure mold $30^{\circ} \mathrm{C}, 38,20^{\circ} \mathrm{C}$ pada temperatur mold $40^{\circ} \mathrm{C}$, dan 39,08 pada temperatur mold $50^{\circ} \mathrm{C}$. Sehingga perpindahan kalor yang terjadi sebesar $107.062,45$ Joule pada suhu $30^{\circ} \mathrm{C}, 80.922,87$ Joule pada suhu $40^{\circ} \mathrm{C}$, dan $72.845,64$ Joule pada suhu $50^{\circ} \mathrm{C}$.

2. Variasi temperatur mold tidak berpengaruh pada potensi sinkmark yang terjadi berdasarkan hasil simulasi menggunakan software Autodesk Moldflow Adviser, karena nilai yang dihasilkan sangat kecil, bahkan hanya beberapa micron. Nilai potensi sinkmark yang diperoleh sebesar $0,1084 \mathrm{~mm}$ pada suhu $30^{\circ} \mathrm{C}, 0,1129$ $\mathrm{mm}$ pada suhu $40^{\circ} \mathrm{C}$, dan $0,1169 \mathrm{~mm}$ pada suhu $50^{\circ} \mathrm{C}$. Dari nilai tersebut potensi sinkmark tidak akan begitu terlihat pada prosuk atau samar karena surface produk akan dilakukan proses finishing etching, sehingga cacat produk sinkmark akan lebih samar. Dan untuk potensi warpage berbanding lurus dengan temperatur mold, dengan kenaikan yang konstan sesai dengan kenaikan temperatur mold. Besaran nilai potensi warpage sebesar $1,418 \mathrm{~mm}$ pada suhu $30^{\circ} \mathrm{C}, 1,521 \mathrm{~mm}$ pada suhu $40^{\circ} \mathrm{C}$, dan $1,632 \mathrm{~mm}$ pada suhu $50^{\circ} \mathrm{C}$. Dikarenakan produk tersebut tidak berpasangan atau berhubungan dengan produk plastik yang lain, jadi dengan besaran nilai warpage tersebut produk masih aman dan dianggap ok untuk kualitasnya.

3. Berdasarkan hasil simulasi dan penelitian yang telah dilakukan parameter setting yang terbaik diantar tiga data yang diperoleh adalah pada temperatur mold $50^{\circ} \mathrm{C}$, karena kualitas produk yang dihasilkan hampir sama dan secara fungsi masih dalam kategori baik, akan tetapi memiliki cycle time atau waktu produksi yang lebih kecil. Sehingga dapat membuat proses produksi lebih efektif dan efisien. 


\section{DAFTAR PUSTAKA}

[1] Y. Yang, X. Chen, N. Lu, and F. Gao, Injection Molding Process Control, Monitoring, and Optimization. Muchen: Hanser, 2016

[2] R.J. Crawford, Plastic Engineering Third Edition. Oxford: Butterworth-Heinemann.,1998.

[3] T. Schimanski, High-Performance Polypropylene Structures for Eco-Friendly, Fully Recyclable Composites. Eindhoven: Technische Universiteit Eindhoven, 2002 DOI: 10.6100/IR555619.

[4] R. O. Ebewele, Polymer science and technology. Florida: CRC Press LLC, 2000.

[5] J.P. Holman, Perpindahan Kalor. Jakarta : Erlangga, 1994.

[6] Injection Molding. http://imdia.or.id/indonesian/dictionary/index.html . Diakses pada 27 Januari 2019 pukul 12.39 .

[7] J. K. Ferrell and E. P. Stahel, "Heat transfer," Ind. Eng. Chem., vol. 58, no. 12, pp. 42-54, 1966.

[8] K. Thulukkanam, Heat Exchanger Design Handbook Second Edition. Florida: CRC Press, 2013.

[9] G. A. A. V. Haagh and F. N. Van De Vosse, "Simulation of three-dimensional polymer mould filling processes using a pseudo-concentration method," Int. J. Numer. Methods Fluids, vol. 28, no. 9, pp. 13551369,1998

[10] M.A. Crowd, Kimia Polimer. Bandung: ITB, 1991.

[11] Y. Liu, Heat transfer process between polymer and cavity wall during injection molding. Chemintz : Universitatsverlag Chemintz, 2014. 